\title{
THE ELECTRODE EQUILIBRIUM OF THE STANDARD CELL.
}

\author{
F. A. Wolff and C. E. Waters. ${ }^{1}$
}

Some experiments described by Hulett ${ }^{2}$ indicating the existence of a state of unstable equilibrium in the Weston cell have, on account of the importance of the subject, led to a further study of the question at the Bureau of Standards.

The equilibrium between cadmium amalgam and cadmium sulphate was first studied. Saturated solutions of the latter were shaken up in air, nitrogen, hydrogen, and in vacuo with cadmium amalgam, but in no case did the electromotive force of cells set up with the treated and untreated solutions differ more than Io microvolts, even though the samples shaken in the presence of air had become cloudy from the formation of an excess of basic cadmium sulphate.

The equilibrium of the system mercury, mercurous sulphate, cadmium sulphate, and of the corresponding system of the Clark cell was then studied in special cells, so constructed that the above materials could be rotated and the effect determined without opening the cell.

This consisted of a tube about $2 \mathrm{~cm}$ in diameter and $\mathrm{I} 2 \mathrm{~cm}$ long, provided at the lower end with a small bulb into which a platinum wire was sealed. The bulb was connected to the main tube by a narrow neck, so that, with sufficient mercury in the cell, the platinum terminal was not in contact with the solution, even during rotation.

${ }^{1}$ An abstract of this paper was read at the New York meeting of the American Physical Society, December, I906, Phys. Rev., 24, 25I; 1907.

${ }^{2}$ Phys. Rev., 23, г66; 1906. 
A shorter internal tube about $\mathrm{I} \mathrm{cm}$ in diameter with several lateral openings, sealed in at the other end of the main tube, was charged with amalgam and crystals of cadmium or zinc sulphate, which were held in place by a plug of asbestos. Contact with the amalgam was made by means of a platinum wire, protected from the solution by sealing it into a glass tube, which extended through the upper seal made after the introduction of the above materials.

The mercurous sulphate and cadmium sulphate or zinc sulphate crystals were introduced over the mercury throngh a side tube by which the cell was exhausted and through which a saturated solution of cadmium or zinc sulphate was subsequently introduced. After filling, the side tube was sealed off, leaving only a small air bubble in the cell, thus practically eliminating any possible influence of air.

The cells were then placed in holders so arranged that one dozen could be simultaneously rotated at any desired speed, with their axes parallel to the axis of rotation and inclined at a small angle to the horizontal, thus insuring a thorough stirring of the paste and mercury with the electrolyte, even at five or six revolutions per ininute. The measurements were made in an automatically controlled oil bath at $25^{\circ}$, immediately after stopping the rotation and raising the holder to a vertical position under the oil. Altogether I2 Weston and 5 Clark cells of this type were set up with samples of mercurous sulphate, made not only by the electrolytic method but also by several chemical methods. The mercurous sulphate was washed in a Gooch crucible three times with I : 6 sulphuric acid, six times with absolute alcohol, and three times with saturated zinc or cadmium sulphate solution. The data and results are given in the following tables: 


\section{TABLE I.}

\section{Weston Rotating Cells.}

\begin{tabular}{|c|c|c|c|c|c|c|c|}
\hline \multirow{3}{*}{$\begin{array}{ll}\text { Cell } \\
\mathrm{R} & 1\end{array}$} & \multirow{3}{*}{$\begin{array}{c}\begin{array}{c}\text { Date } \\
\text { Igo6 }\end{array} \\
\text { Oct.13 }\end{array}$} & \multirow{3}{*}{$\begin{array}{c}\mathrm{CdSO}_{4} \\
\\
\text { Purified by } \\
\text { Recrys- } \\
\text { talliza- } \\
\text { tion. }\end{array}$} & \multirow{3}{*}{$\begin{array}{c}\mathrm{Cd}_{\mathrm{d}} \\
\text { Amalg. } \\
12 \frac{1}{2} \% \text { Kahl. } \\
\text { El.Dist. }\end{array}$} & \multirow{3}{*}{$\begin{array}{l}\text { Mercury } \\
\text { Distilled } \\
\text { at reduced } \\
\text { pressure. }\end{array}$} & \multicolumn{3}{|r|}{$\mathrm{Hg}_{2} \mathrm{SO}_{4}$} \\
\hline & & & & & \multicolumn{2}{|c|}{ Sample } & \multirow{2}{*}{$\begin{array}{r}\text { Method of Preparation } \\
\text { Electrolytic }(D=5 ; V=.5)\end{array}$} \\
\hline & & & & & $\mathrm{b}_{13}$ & gray & \\
\hline$* \mathrm{R} 11$ & Oct. 30 & " & “ & “ & $\mathrm{b}_{13}$ & gray & Electrolytic $(\mathrm{D}=5 ; \mathrm{V}=.5)$ \\
\hline$\dagger \mathrm{R} 12$ & Oct.30 & “ & ، & “ & $\mathrm{b}_{13}$ & gray & Electrolytic $(\mathrm{D}=5 ; \mathrm{V}=.5)$ \\
\hline R 3 & 0ct.13 & “ & “ & “ & $\mathrm{e}_{3}$ & gray & By action of $\mathrm{HN}_{2} \mathrm{O}_{3}$ and $\mathrm{H}_{2} \mathrm{SO}_{4}$ on $\mathrm{Hg}$ \\
\hline R 5 & 0ct.16 & ، & “ & ، & $d_{2}$ & gray & From $\mathrm{HgNO}_{3}$ and $\mathrm{H}_{2} \mathrm{SO}_{4}$ \\
\hline $\mathrm{R} 6$ & 0ct.16 & “ & “ & ، & c & gray & By action of fuming $\mathrm{H}_{2} \mathrm{SO}_{4}$ on $\mathrm{Hg}$ \\
\hline $\mathrm{R} 2$ & 0ct.13 & “ & “ & ، & $a_{12}$ & white & \\
\hline$\ddagger \mathrm{R} 8$ & 0ct.30 & “ & “ & “ & $a_{12}$ & white & Electrolytic $\left(\mathrm{D}=.251: 16 \quad \mathrm{H}_{2} \mathrm{SO}_{4}\right)$ \\
\hline R 4 & 0ct.16 & “6 & “ & $\lll$ & $a_{9}$ & white & \\
\hline$\ddagger \mathrm{R} 10$ & 0ct.30 & “6 & “ & “ & $\mathrm{a}_{9}$ & white & \\
\hline R 7 & 0ct.16 & “ & “ & ، & $\mathrm{i}_{2}$ & white & By digestion of Coml. Sample with \\
\hline$\ddagger \mathrm{R} 9$ & 0ct. 30 & “ & “ & “ & $\mathrm{i}_{2}$ & white & $\int \mathrm{H}_{2} \mathrm{SO}_{4}$ \\
\hline
\end{tabular}

* Platinum terminal exposed to paste.

$\dagger$ Basic cadmium sulphate added to paste.

$\ddagger$ Mercurous sulphate rotated with saturated $\mathrm{CdSO}_{4}$ solution $2^{\frac{3}{4}}$ days before its introduction into the cells.

TABLE II.

Clark Rotating Cells.

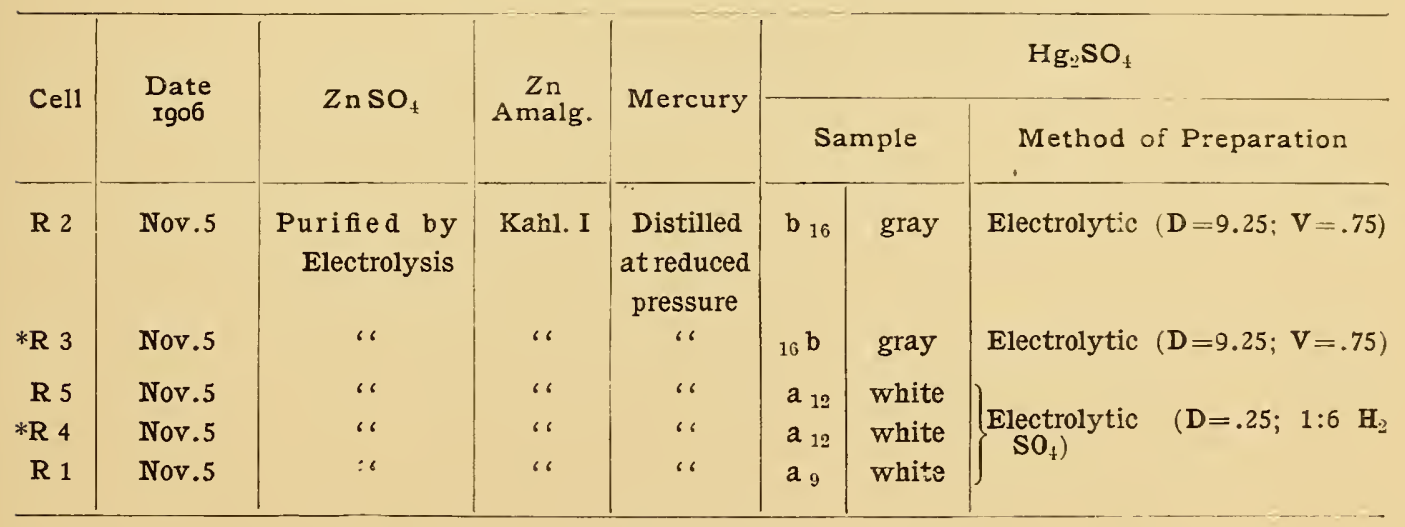

* Zinc oxide added to paste. 


\section{TABLE III.}

\section{Weston Rotation Cells.}

[Differences in microvolts from mean of reference cells.]

\begin{tabular}{|c|c|c|c|c|c|c|c|c|c|c|c|c|c|c|}
\hline \multirow{2}{*}{ Date } & \multicolumn{3}{|c|}{ R 1} & \multicolumn{3}{|c|}{ R 11} & \multicolumn{2}{|c|}{ R 12} & \multicolumn{2}{|c|}{ R 3} & \multicolumn{2}{|c|}{ R 5} & \multicolumn{2}{|c|}{ R 6} \\
\hline & Diff. & Tir & ne & Diff. & Tin & & Diff. & Time & Diff. & Time & Diff. & Time & Diff. & Time \\
\hline & & D. & H. & & D. & & & D. H. & & D. $\mathbf{H}$. & 1 & D. H. & & D. $\mathrm{H}$. \\
\hline Oct. $18, ' 06$ & +72 & & 0 & & . & & 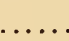 & ......... & +89 & 0 & +83 & 0 & +92 & 0 \\
\hline ، 19 & +43 & & 0 & & & & & & +59 & 0 & +59 & 0 & +67 & 0 \\
\hline ، 20 & +11 & & 0 & & & & & & +24 & 0 & +34 & 0 & +39 & 0 \\
\hline “ 22 & +29 & & 0 & & & & & & +39 & 0 & +54 & 0 & +55 & 0 \\
\hline 23 & +44 & & 15 & & & & & & +53 & 15 & +57 & 15 & +66 & 15 \\
\hline 6 $\quad 24$ & +42 & & 18 & & & & & & +57 & 18 & +88 & 18 & +43 & 18 \\
\hline 25 & +45 & & 9 & & & & & & +41 & 19 & +103 & 19 & +41 & 19 \\
\hline 《 27 & +63 & 3 & 1 & & & & & & +64 & 31 & +142 & 31 & +58 & 3 \\
\hline C6 29 & +88 & 5 & 1 & & & & & & +88 & $\begin{array}{ll}5 & 1\end{array}$ & +149 & 51 & +83 & 5 \\
\hline " 31 & +61 & 6 & 21 & -4 & & 0 & -11 & 0 & +69 & 621 & +93 & 621 & +56 & 621 \\
\hline Nov. 5 & +73 & 10 & 14 & +55 & 3 & 7 & +37 & 37 & +83 & 1014 & +90 & 1014 & +65 & 1014 \\
\hline ، 8 & +66 & 12 & 17 & +79 & & 11 & -17 & 511 & +67 & 1217 & +104 & 1217 & +46 & 1217 \\
\hline \& 12 & +72 & 16 & 12 & +69 & 9 & 0 & -31 & 96 & +69 & 1612 & +71 & 1612 & +52 & 1612 \\
\hline 16 & +64 & 20 & 8 & +116 & & 20 & -54 & 132 & +70 & 208 & +50 & 208 & +55 & 208 \\
\hline “) 19 & +59 & 23 & 5 & +139 & 15 & 17 & -36 & 1523 & +69 & 235 & +47 & 235 & +54 & 23 \\
\hline “ 24 & +50 & 28 & 4 & +204 & 20 & 16 & -26 & 2022 & +71 & $28 \quad 4$ & +41 & 284 & +54 & 28 \\
\hline ، 30 & +35 & 28 & 8 & +117 & 20 & 20 & -37 & 212 & +35 & $28 \quad 8$ & +29 & 288 & +32 & 28 \\
\hline Dec. 5 & +31 & 28 & 8 & +93 & 20 & 20 & -39 & 212 & +33 & $28 \quad 8$ & +26 & 288 & +30 & 28 \\
\hline " 10 & +46 & & 1 & +240 & 24 & 13 & -8 & 2419 & +74 & 321 & +40 & $32 \quad 1$ & +54 & 32 \\
\hline ، 14 & +50 & 35 & 16 & +271 & 28 & 4 & -25 & 2810 & +74 & 3516 & +45 & 3516 & +53 & 3516 \\
\hline ، 21 & & & & +348 & 33 & 21 & -17 & 3412 & +92 & 4118 & +41 & 4118 & +38 & $41 \quad 18$ \\
\hline Jan. $5,{ }^{\prime} 07$ & & & & +520 & 46 & 12 & -32 & 473 & +67 & 547 & +41 & 547 & +19 & 547 \\
\hline ، 10 & & & & +567 & & 6 & -27 & 5120 & +66 & $59 \quad 4$ & +47 & 594 & +28 & 594 \\
\hline “ 14 & & & & +427 & 52 & 18 & -34 & 548 & +51 & 6116 & +40 & 6116 & +13 & 6116 \\
\hline " 24 & & & & +749 & 61 & 12 & -26 & 6216 & +66 & 700 & +46 & 700 & +33 & 700 \\
\hline ، 30 & & & & +926 & 67 & 2 & -36 & 686 & +50 & 7522 & +42 & 7522 & +24 & $75 \quad 22$ \\
\hline Feb. 5 & & & & +1030 & 71 & & -36 & 736 & +49 & 8021 & +37 & 8021 & +32 & 8021 \\
\hline “ 8 & & & & +1073 & 72 & 21 & -35 & 7418 & +46 & 829 & +38 & 829 & +28 & 829 \\
\hline Mar. 1 & & & & & $\ldots$ & & -43 & 9314 & -38 & 1015 & +38 & 1015 & +35 & 1015 \\
\hline 《 12 & & & & & & & -42 & 10214 & -29 & 1105 & +32 & 1105 & +40 & 1105 \\
\hline Apr. 5 & & & & & & & -41 & 1214 & -8 & 12819 & +90 & 12819 & +51 & 12819 \\
\hline “ 10 & & & & & & ‥ & -34 & 12410 & -10 & 1321 & +94 & 1321 & +76 & 1321 \\
\hline May 25 & & & & & & & -38 & 1354 & -7 & 14219 & +127 & 14219 & +84 & 14219 \\
\hline June 4 & & & & & & . & --34 & 14420 & -3 & 15211 & +135 & 15211 & +95 & 15211 \\
\hline “ 7 & & & & & & & -37 & 14718 & +2 & 1559 & +142 & 1559 & +94 & 1559 \\
\hline "6 15 & & & & ... & $\cdots$ & ... & -37 & 1556 & -3 & 16221 & +169 & 16221 & +99 & 16221 \\
\hline Aug.15 & & & & +494 & 72 & & -40 & 1556 & -5 & 16221 & +44 & 16221 & +43 & 16221 \\
\hline Sept.27 & & & & +571 & & 21 & -41 & 1556 & -6 & 16221 & +38 & 16221 & +23 & 16221 \\
\hline
\end{tabular}


TABLE III.

\section{Weston Rotation Cells.}

[Differences in microvolts from mean of reference cells.]

\begin{tabular}{|c|c|c|c|c|c|c|c|c|c|c|c|c|c|c|c|c|c|}
\hline \multicolumn{3}{|c|}{ R 2} & \multicolumn{3}{|c|}{ R 8} & \multicolumn{3}{|c|}{ R 4} & \multicolumn{3}{|c|}{ R 10} & \multicolumn{3}{|c|}{ R 7} & \multicolumn{3}{|c|}{ R9 } \\
\hline Diff. & Tin & & Diff. & Tim & & Diff. & Tir & me & Diff. & Tin & & Diff. & Tir & ne & Diff. & $\mathrm{Ti}_{1}$ & me \\
\hline+148 & D. & $\begin{array}{r}\text { H. } \\
0\end{array}$ & & $\begin{array}{c}\text { D. } \\
\ldots \ldots\end{array}$ & $\begin{array}{l}\text { H. } \\
\ldots .\end{array}$ & +137 & D. & $\begin{array}{r}\text { H. } \\
0\end{array}$ & & $\begin{array}{l}\text { D. } \\
\ldots\end{array}$ & $\begin{array}{l}\text { H. } \\
\ldots\end{array}$ & +93 & D. & $\begin{array}{r}\text { H. } \\
0\end{array}$ & & & \\
\hline+115 & & 0 & & & $\ldots$ & +100 & & 0 & & $\ldots \ldots$ & & +49 & & 0 & & & $\ldots$ \\
\hline+59 & & 0 & & & $\ldots$ & +69 & & 0 & & . & & +10 & & 0 & & & \\
\hline+98 & & 0 & & & & +94 & & 0 & & & & $\ldots \ldots$ & & 0 & & & \\
\hline+103 & & 15 & & & $\ldots$ & +95 & & 15 & & 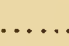 & & +46 & & 15 & & & \\
\hline+220 & & 18 & & & $\ldots$ & +252 & & 18 & & & & +115 & & 18 & & & \\
\hline+275 & 1 & 9 & & & $\ldots$ & +354 & 1 & 9 & 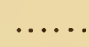 & 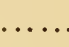 & & +173 & 1 & & & & \\
\hline+245 & 3 & 1 & & & $\ldots$ & +316 & 3 & 1 & & & & +168 & 3 & & & & \\
\hline+313 & 5 & 1 & $\ldots \ldots$ & & $\ldots$ & +363 & 5 & 1 & ....... & & $\ldots$ & +178 & 5 & 9 & & & \\
\hline+321 & 6 & 21 & -9 & & 0 & +441 & 6 & 21 & +216 & & 0 & +111 & 7 & 5 & +76 & & 0 \\
\hline+340 & 10 & 14 & +515 & & 7 & +440 & 10 & 14 & +590 & 3 & 7 & +187 & 10 & 22 & +295 & 3 & 7 \\
\hline+329 & 12 & 17 & +474 & 51 & 11 & +572 & 12 & 17 & +556 & & 11 & +141 & 13 & 2 & +249 & & 11 \\
\hline+292 & 16 & 12 & +389 & & 0 & +429 & 16 & 12 & +501 & 9 & 0 & +97 & 16 & 0 & +186 & 9 & 0 \\
\hline+279 & 20 & 8 & +380 & 122 & 20 & +810 & 20 & 8 & +440 & 12 & 20 & +90 & 19 & 20 & +187 & 12 & 20 \\
\hline+259 & 23 & 5 & +414 & 15 & 17 & +754 & 23 & 5 & +479 & 15 & 17 & +81 & 22 & 16 & +159 & 15 & 17 \\
\hline+237 & 28 & 4 & +364 & 20 & 16 & +754 & 28 & 4 & +389 & 20 & 16 & +61 & 27 & 16 & +104 & 20 & 16 \\
\hline+152 & 28 & 8 & +272 & 20 & 20 & +655 & 28 & 8 & +265 & 20 & 20 & +57 & 27 & 19 & +93 & 20 & 20 \\
\hline+136 & 28 & 8 & +228 & 20 & 20 & +613 & 28 & 8 & +234 & 20 & 20 & +52 & 27 & 19 & +85 & 20 & 20 \\
\hline+204 & 32 & 1 & +337 & 24 & 13 & +931 & 32 & 1 & +336 & 24 & 13 & +69 & 31 & 12 & +107 & 24 & 13 \\
\hline+194 & 35 & 16 & +336 & 28 & 4 & +1092 & 35 & 16 & +314 & 28 & 4 & +68 & 35 & 3 & +106 & 28 & 4 \\
\hline+191 & 41 & 18 & & & & & & & +248 & 33 & 21 & +74 & 40 & 20 & +95 & 33 & 21 \\
\hline+150 & 54 & 7 & & & & & & & +207 & 45 & 12 & +63 & 53 & 12 & +63 & 46 & 12 \\
\hline+147 & 59 & 4 & & & & & & & +207 & 50 & & +58 & 57 & 6 & +72 & 50 & 6 \\
\hline+126 & 61 & 16 & & & & & & & +195 & 52 & 18 & +70 & 59 & 17 & +53 & 52 & 18 \\
\hline+56 & 70 & & & & & & & & +196 & 61 & 12 & +73 & 68 & 12 & +72 & 61 & 12 \\
\hline+110 & 75 & 22 & & & & & & & +146 & 67 & 2 & +50 & 74 & 2 & +36 & 67 & 2 \\
\hline+115 & 80 & 21 & & & & & & & +135 & 71 & & +44 & 78 & 10 & +38 & 71 & 10 \\
\hline+113 & 82 & 9 & & & & & & & +139 & 72 & 21 & +45 & 79 & 21 & +33 & 72 & 21 \\
\hline+118 & 101 & 5 & & & & & & & & & & & & & & & \\
\hline+60 & 110 & 5 & & & & & & & & & & & & & & & \\
\hline+115 & 128 & 19 & & & & & & & & & & & & & & & \\
\hline+114 & 132 & 1 & & & & & & & & & & & & & & & \\
\hline+113 & 142 & 19 & & & & & & & & & & & & & & & \\
\hline+115 & 152 & 11 & & & & & & & & & & & & & & & \\
\hline+111 & 155 & 9 & & & & & & & & & & & & & & & ... \\
\hline+135 & 162 & 21 & & & & & & & & & & & & & & & .... \\
\hline+15 & 162 & 21 & & & & & & & +55 & 72 & 21 & +36 & 79 & 21 & +12 & 72 & 21 \\
\hline+7 & 162 & 21 & & & & & & & +55 & 72 & & +28 & 79 & 21 & +13 & 72 & \\
\hline
\end{tabular}


TABLE IV.

Clark Rotation Cells.

[Differences in microvolts from mean of reference cells.]

\begin{tabular}{|c|c|c|c|c|c|c|c|c|c|c|c|c|c|c|}
\hline \multirow{3}{*}{ Date } & \multicolumn{2}{|c|}{$\mathbf{R} 2$} & \multicolumn{3}{|c|}{ R 3} & \multicolumn{3}{|c|}{ R 5} & \multicolumn{3}{|c|}{ R 4} & \multicolumn{3}{|c|}{ R 1} \\
\hline & Diff. & Time & Diff. & Tin & & Diff. & Tin & & Diff. & Tin & & Diff. & Tin & \\
\hline & & D. $\mathrm{H}$. & & D. & H. & & D. & H. & & D. & & & D. & \\
\hline Nov. $6,{ }^{\prime} 06$ & -25 & 0 & -120 & & 0 & 0 & & 0 & -140 & & 0 & +13 & & 0 \\
\hline Nov. 7 & -13 & 22 & -130 & & 22 & +30 & & 22 & -50 & & 22 & +27 & & 22 \\
\hline Nov. 8 & +16 & 122 & -54 & 1 & 22 & +59 & 1 & 22 & -26 & 1 & 22 & +49 & 1 & 22 \\
\hline Nov. 12 & +16 & 4. 16 & +45 & 4 & 16 & +100 & 4 & 16 & +25 & 4 & 16 & +90 & 4 & 16 \\
\hline Nov. 16 & +17 & $8 \quad 13$ & +2 & 8 & 13 & +89 & 8 & 13 & +2 & 8 & 13 & +72 & 8 & 13 \\
\hline Nov. 24 & +21 & 169 & +4 & 16 & 9 & +89 & 16 & 9 & \pm 0 & 16 & 9 & +81 & 16 & 9 \\
\hline Nov. 30 & +36 & $16 \quad 12$ & +18 & 16 & 12 & +61 & 16 & 12 & -5 & 16 & 12 & +46 & 16 & 12 \\
\hline Dec. 5 & +22 & $16 \quad 12$ & -20 & 16 & 12 & +45 & 16 & 12 & -43 & 16 & 12 & +22 & 16 & 12 \\
\hline Dec. 10 & +22 & 206 & +202 & 20 & 6 & +72 & 20 & 6 & -34 & 20 & 6 & +22 & 20 & 6 \\
\hline Dec. 14 & +21 & $23 \quad 20$ & +273 & 23 & 20 & +113 & 23 & 20 & +98 & 23 & 20 & +8 & 23 & 20 \\
\hline Dec. 21 & +26 & $29 \quad 22$ & +22 & 29 & 22 & +34 & 29 & 22 & +20 & 29 & 22 & -36 & 29 & 22 \\
\hline Jan. $5,{ }^{\prime} 07$ & 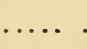 & & -217 & 42 & 14 & -136 & 42 & 14 & -17 & 42 & 14 & +12 & 42 & 14 \\
\hline Jan. 10 & & & -243 & 47 & 10 & -141 & 47 & 10 & -3 & 47 & 10 & +7 & 47 & 10 \\
\hline Jan. 14 & & & -160 & 49 & 22 & -199 & 49 & 22 & -50 & 49 & 22 & -99 & 49 & 22 \\
\hline Jan. 24 & & & +5 & 58 & 7 & -5 & 58 & 7 & -47 & 58 & 7 & +157 & 58 & 7 \\
\hline Jan. 30 & & & +20 & 64 & 4 & -159 & 64 & 4 & -35 & 64 & 4 & -33 & 64 & 4 \\
\hline Feb. 5 & & & +16 & 69 & 4 & -155 & 69 & 4 & -26 & 69 & 4 & -48 & 69 & 4 \\
\hline Feb. 8 & & & +17 & 70 & 16 & -145 & 70 & 16 & -23 & 70 & 16 & -4 & 70 & 16 \\
\hline Mar. 1 & & & -17 & 89 & 12 & -143 & 89 & 12 & -37 & 89 & 12 & -97 & 89 & 12 \\
\hline Mar. 12 & & & -20 & 98 & 12 & -182 & 98 & 12 & -60 & 98 & 12 & -227 & 98 & 12 \\
\hline Apr. 5 & 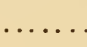 & & -88 & 117 & 2 & -68 & 117 & 2 & -28 & 117 & 2 & -108 & 117 & 2 \\
\hline Apr. 10 & & & -91 & 120 & 8 & -59 & 120 & 8 & -43 & 120 & 8 & -145 & 120 & 8 \\
\hline May 25 & & & $\ldots \ldots$ & $\ldots \ldots$ & $\ldots$ & -76 & 131 & 2 & -79 & 131 & 2 & +174 & 131 & 2 \\
\hline June 4 & & & & & $\cdots$ & -91 & 140 & 18 & -84 & 140 & 18 & -216 & 140 & 18 \\
\hline June 7 & & & -47 & 143 & 16 & -79 & 143 & 16 & -62 & 143 & 16 & ….. & $\cdots \cdot$ & $\cdots$ \\
\hline June 15 & & & ....... & & & -86 & 151 & 4 & -76 & 151 & 4 & +3 & 151 & 4 \\
\hline
\end{tabular}


It will be seen that no initial low values, as observed by Hulett, were obtained. The Weston cells with gray samples of mercurous sulphate show changes which do not exceed o.or per cent even after continuing the rotation four months, except in one case in which the platinum terminal was purposely exposed. In this cell the terminal was inadvertently amalgamated, but was treated with aqua regia to remove the mercury before filling. The white samples generally showed considerably larger effects, but not as great as those observed by Hulett. There was also a tendency to reacli a maximum value, and then, on further rotation, to approach the normal.

Cell No. I2, in which basic cadmium sulphate ${ }^{3}$ was added in excess to the cadmium sulphate solution, gave approximately normal results from the first, although the paste was quite yellow.

Although the Clark cells showed smaller effects than the Weston cells, there seem to be slight differences produced by rotation. Cells 3 and 4 , in which an excess of zinc oxide was added to the zinc sulphate solution, showed only a slight difference; but after an interruption of the rotation for several days the paste caked and the results subsequently obtained were irregular. The irregularities of the remaining Clark cells subsequent to December 5 may possibly be due to the cracking of the protecting tube about the platinum wire imbedded in the amalgam. Owing to the construction employed, this can not be determined without destroying the cell.

On December 19, r9o6, the Weston cells I, 4, and 8 were opened and the paste used in setting up cells of the ordinary form. The gray sample from cell No. I gave, after two days, practically the same value as in the rotating cell. It has slowly decreased and at present is within 25 microvolts of the normal. The two cells set up with the white samples showed abnormally high values, 600 and 400 microvolts, respectively, both of which steadily decreased until March 25, 1907. On that date they were transferred from the bath in which they had been kept continuously at $25^{\circ}$ to another at $20^{\circ}$ ?

${ }^{3}$ Made by adding sufficient ammonia to a solution of cadmium sulphate to dissolve the precipitate first formed, filtering into a large rolume of water, collecting, washing, and gently igniting the precipitate. 
While only a very slight hysteresis was observed in the case of our Weston cells, particularly when finely crushed cadmium sulphate crystals were employed in the paste and over the amalgam, the two cells in question showed marked effects of this character. These persisted, with slight changes from day to day, for a long period, indicating either that a surface film was formed on the crystals during rotation or that a large excess of cadmium sulphate was employed in the paste, thus retarding the attainment of saturation equilibrium. A similar effect has been observed in a number of $\mathrm{H}$ cells in which the paste contained a large excess of cadmium sulphate crystals.

The results obtained show that not all samples of mercurous sulphate exhibit the behavior observed by Hulett, as gray samples, prepared by different methods, are changed by rotation for months by less than o.oI per cent. ${ }^{4}$ This difference is small enough to be possibly accounted for by attrition during rotation, thus introducing the effect of size of grain, noticed by von Steinwehr.

It does not appear to the authors that the high values shown by some of the rotation cells throw any light upon the decrease below the normal electromotive force observed by Hulett in some cells of the ordinary type. According to him the first reaction which takes place when the cell is set up is a hydrolysis by which the concentration of the mercury ions is increased. Opposing this is a reaction between the mercury and the products of hydrolysis in solution, which reduces the concentration of the mercury ions. The secondary products formed in this reaction would, therefore, be responsible for the decrease observed by him in cells of the ordinary type. As it is evident that this effect can not be due directly to the formation of new inercury compounds in the presence of an excess of mercurous sulphate, since the concentration of the mercury ions would thereby be increased, it must. on this theory, be caused by other products of the reaction.

In the rotation cells the amount of these secondary products would depend upon the duration of the rotation and on the area of the mercury surface exposed to the solution. According to Hulett's

\footnotetext{
${ }^{4}$ While the samples of mercurous sulphate prepared by Hulett are in practical agreement with our own, as shown by cells set up with exchange samples, his cells differ from those made at the Bureau by about one-third of the above amount.
} 
explanation, the slight effects observed by us with gray samples of mercurous sulphate, which owe their color to the presence of finely divided mercury, would be due, not to decreased hydrolysis, but to the acceleration of the secondary reaction. It would, therefore, follow that such samples should give abnormally low values after stopping the rotation. As in no case was this result obtained, the authors conclude that the effect must be due to some other cause.

In view of the various questions which have arisen in connection with the results described in this paper, it is proposed to continue the investigation.

WASHINGTON, October 4, I907. 